\title{
Olhares de mães de grupos populares sobre educação sexual de filhos adolescentes
}

\section{Perspective of mothers of popular groups about the sexual education of their adolescent children}

\section{La visión de madres de grupos populares sobre la educación sexual de hijos adolescentes}

\author{
Sabrina Dal Ongaro Savegnago* \\ Universidade Federal do Rio de Janeiro - UFRJ, Rio de Janeiro, Rio de Janeiro, Brasil \\ Dorian Mônica Arpini** \\ Universidade Federal de Santa Maria - UFSM, Santa Maria, Rio Grande do Sul, Brasil
}

\begin{abstract}
RESUMO
Este estudo buscou conhecer os olhares de mães de grupos populares a respeito dos diálogos sobre sexualidade com seus filhos adolescentes, principalmente no que se refere aos desafios enfrentados e aos papeis atribuídos à escola e aos serviços de saúde pública. Realizaram-se entrevistas semiestruturadas e grupos focais. Os resultados evidenciaram que as mães participantes têm apresentado dificuldades para dialogar sobre sexualidade com os filhos. A escola foi apontada como uma importante fonte de informação. As participantes destacaram também os serviços de saúde como importante recurso a ser utilizado pelos filhos e pelas próprias mães. As considerações finais apontam para a relevância das instituições escolares e de saúde na educação sexual dos adolescentes, entendendo as mesmas como complementares à abordagem da família. Destaca-se ainda a complexidade da temática e a importância do preparo dos profissionais de saúde e educação para tratar do tema, entendendo que estes quando capacitados podem se converter em importante fonte de auxílio para os pais, facilitando a abordagem.
\end{abstract}

Palavras-chave: adolescência, relações familiares, sexualidade, educação.

\section{ABSTRACT}

This study aimed to understand the perspective of mothers of popular groups concerning dialogues about sexuality with their adolescent children, mainly regarding to the challenges they face, the roles attributed to the school and the public health services. Semi-structured interviews and focal groups were carried out. Results evidenced that the participant mothers have presented difficulties to talk about sexuality with their children. The school was mentioned as an important source of information. Mothers also highlighted the health service as an important resource to be used by them and their children. Final considerations point out the relevance of the school and health institutions regarding the sexual education of adolescent, considering them as additional to the approach of the family. The complexity 
of the theme and the importance of the training of the health care and education professionals to discuss the subject are highlighted, considering that trained professionals may be an important source of help for the parents, facilitating their approach of the adolescents.

Keywords: adolescence, family relations, sexuality, education.

\section{RESUMEN}

Este estudio tuvo como objetivo conocer la visión de las madres de grupos populares acerca de los diálogos sobre sexualidad con sus hijos adolescentes, principalmente en lo referente a los desafíos enfrentados y las funciones atribuidas a la escuela y a los servicios de salud pública. Fueron realizadas entrevistas semiestructuradas y grupos focales. Los resultados mostraron que las madres participantes han presentado dificultades para dialogar sobre sexualidad con sus hijos. La escuela fue identificada como una importante fuente de información. Las participantes también destacaron los servicios de salud como un importante recurso para ser utilizado por sus hijos y por las propias madres. Las consideraciones finales apuntan a la relevancia de las instituciones educativas y de salud en la educación sexual de los adolescentes, considerando las mismas como complementarias al enfoque de la familia. También se destaca la complejidad de la temática y la importancia de la preparación de los profesionales de la salud y de la educación para tratar del tema, pues se entiende que estos cuando capacitados pueden convertirse en importante fuente de ayuda para los padres, lo que facilita el abordaje.

Palabras clave: adolescencia, relaciones familiares, sexualidad, educación.

\section{I ntrodução}

A adolescência é um conceito relativamente recente, o qual teve sua origem na sociedade moderna ocidental, ou seja, trata-se de um fenômeno social e historicamente construído. Ressalta-se sua condição de não-universalidade, uma vez que ainda hoje existem sociedades nas quais a adolescência não é reconhecida (Sprinthall \& Collins, 2003). Apesar de diversas contribuições da literatura referirem-se à adolescência no seu aspecto geral e universal, muitas experiências e estudos mais recentes em torno deste tema têm apontado para uma diversidade de vivências marcando o período de desenvolvimento desse grupo social. Desse modo, ao se considerar o contexto social, econômico, político e cultural onde o sujeito está inserido, o que implica em uma diversidade, é possível falar em "adolescências" (Arpini \& Witt, 2015). Neste sentido, a definição deste período de desenvolvimento do sujeito não se constitui mais em uma tarefa que implica em estabelecer regras gerais e universais em relação a essa fase da vida, mas indicar algumas características que podem marcar esse período que se definiu como a "etapa entre a infância e vida adulta" (Mayorga, 2006).

Vale salientar que, mesmo em uma perspectiva que considera a adolescência uma construção social, os aspectos psicobiológicos são importantes e fazem parte desta construção. A puberdade, enquanto 
desenvolvimento dos caracteres sexuais secundários e da capacidade reprodutiva, engloba processos fisiológicos que se impõe inexoravelmente ao sujeito (Corso \& Corso, 2011). De acordo com Freud (1905/1996), a puberdade introduz remanejamentos psíquicos, ou seja, ela "constitui o ponto de partida biológico de um processo psíquico cuja tarefa é integrar as modificações que induz" (Emmanuelli, 2008, p. 17).

Ruffino (2004), também a partir de um referencial psicanalítico, considera a puberdade uma "experiência de atravessamento invasora" e distingue duas formas de organização social que produzem formas subjetivas distintas de recepção da experiência pubertária. Nas sociedades tradicionais e comunitárias, segundo o autor, haviam fatores que minimizavam o impacto da puberdade, tais como os rituais de passagem, que ofereciam referenciais coletivos que operavam como organizadores deste processo. Por outro lado, a sociedade moderna ocidental, tendo imposto uma ruptura dos laços societários tradicionais, acaba deixando o jovem desamparado diante da experiência da puberdade. Neste sentido, a adolescência é entendida pelo autor como um trabalho psíquico do sujeito moderno ocidental, que se faz necessário para processar a passagem da infância para a adultez, diante da ausência de dispositivos que cumpram a função que outrora era exercida pelos rituais.

Partimos assim de referenciais da psicanálise freudiana para justificar a importância de se abordar a relação entre adolescência e sexualidade, uma vez que esta entende a adolescência como um processo psíquico organizador da vida do sujeito, principalmente no que concerne à sexualidade. Ou seja, nesse momento, em que há uma retomada do desenvolvimento psicossexual que havia se iniciado na infância, se confere sentido à sexualidade infantil e significado ao que está por vir na vida adulta (Freud, 1905/1996; Marty \& Cardoso, 2008).

Neste sentido, é imprescindível que a família ${ }^{1}$ se constitua em fonte de apoio e segurança para que o adolescente possa compreender as transformações pelas quais está passando e para que possa enfrentar os conflitos e angústias que podem ocorrer, principalmente no que se refere à sexualidade (Preto, 1995; Sousa, Fernandes, \& Barroso, 2006).

No entanto, diversos estudos que analisaram a questão dos diálogos sobre sexualidade no contexto familiar, a partir do ponto de vista de adolescentes, evidenciaram que a sexualidade costuma ser um assunto pouco tratado na família e que a maioria dos pais não oferece abertura para que este tema seja discutido (Borges, Nichiata, \& Schor, 2006; Brandão, 2004; Macedo, Miranda, Pessoa Junior, \& Nobrega, 2013; Savegnago \& Arpini, 2013; Sevilla, Sanabria, Orcasita, \& Palma, 2016). Em um destes estudos, realizado em uma cidade do Rio Grande do Sul com adolescentes de grupos populares, 
as participantes manifestaram curiosidade e desejo de saber sobre o assunto e afirmaram realizar tentativas para que ele fosse tratado na família. Porém, na perspectiva das mesmas, havia por parte dos pais uma atitude de evitar a abordagem do tema (Savegnago \& Arpini, 2013).

Dias e Gomes (1999) ressaltam que o diálogo com os filhos pode ser incômodo para os pais devido ao fato de que eles podem reexperienciar suas próprias dúvidas e angústias adolescentes relativas à sexualidade. Desse modo, o olhar sobre a sexualidade do filho adolescente possibilita que os pais redimensionem e resignifiquem suas próprias experiências relacionadas à sexualidade.

Diante destas dificuldades, muitos pais acabam não se ocupando do importante papel que lhes caberia na abordagem da sexualidade com seus filhos. Assim, outras instituições têm sido importantes complementando a tratamento do tema junto aos adolescentes. As escolas e os serviços de saúde pública são apontados por diversos estudos como instituições que têm assumido uma importância na educação sexual dos adolescentes (Almeida \& Centa, 2009; Borges et al., 2006; Brêtas \& Silva, 2005; Santos, 2011; Santos \& Ressel, 2013; Sevilla et al., 2016; Vilelas Janeiro, 2008). As relações que mães e adolescentes estabelecem com as escolas e os serviços de saúde serão discutidas e problematizadas no decorrer deste artigo.

Destaca-se que a maioria dos estudos mais recentes sobre a questão dos diálogos sobre sexualidade na família são da área da enfermagem, havendo poucas pesquisas da área da Psicologia que tomam como foco esse aspecto. Neste sentido, concordamos com Sarti (2004), que salienta a importância de questionar como a própria família entende suas dificuldades, suas necessidades, suas aspirações e quais são as alternativas que ela encontra para lidar com seus desafios, principalmente no que se refere aos adolescentes. Desse modo, este artigo tem como objetivo analisar, a partir do olhar de mães de grupos populares, os desafios que envolvem os diálogos sobre sexualidade com filhos adolescentes e o papel das instituições escolares e dos serviços de saúde pública no que se refere à educação sexual dos adolescentes.

\section{Método}

\section{Participantes}

A pesquisa foi realizada em um Centro de Referência e Assistência Social (CRAS) de uma cidade do interior do Rio Grande do Sul. A escolha do local relaciona-se à identificação de que, dentre os usuários desta instituição, encontravam-se mães de adolescentes oriundas de grupos populares. Participaram 17 mães de adolescentes, 
usuárias do referido CRAS. Destas, nove foram entrevistadas individualmente (E) e oito participaram de grupos focais. Foram realizados dois grupos focais, com a presença de cinco mães no primeiro (GF1) e três mães no segundo grupo (GF2). A média de idade das participantes foi de 40,94 anos, tendo em média 4,4 filhos. Em relação à escolaridade, a maioria das mães (10), possuía o ensino fundamental incompleto. E em relação à ocupação, oito participantes eram donas de casa, três eram diaristas, duas empregadas domésticas, uma trabalhava com reciclagem de materiais, uma como comerciante, uma como oficineira de artesanato e uma como auxiliar de limpeza. Buscando manter o anonimato das participantes, seus nomes foram substituídos por códigos (por exemplo, M1, M2, M3...) ao longo do texto.

\section{Instrumentos e Procedimentos}

Após a autorização da instituição para a realização da pesquisa e da aprovação do projeto pelo Comitê de Ética em Pesquisa da instituição de ensino superior à qual as autoras estão vinculadas (parecer $\mathrm{n}$ o 54850 e Certificado de Apresentação para Apreciação Ética (CAAE) no 05022712.8.0000.5346), iniciou-se o contato com as prováveis participantes. A maior parte dos contatos foi feito via telefone pela pesquisadora, a partir de indicações das profissionais do CRAS, e de consultas a prontuários e fichas referentes ao programa Bolsa-Família de usuários da instituição e também através da participação da pesquisadora em um dos grupos de mulheres que acontecia quinzenalmente na instituição, durante o qual foi exposta a proposta de pesquisa e realizado o convite às mães ali presentes. Os critérios para inclusão na pesquisa foram: ser mãe de pelo menos um adolescente (do sexo feminino ou masculino), ser usuária do CRAS e ter disponibilidade e interesse em participar da entrevista ou do grupo focal. Neste estudo, partiu-se da disposição do Estatuto da Criança e do Adolescente (1990), que define como adolescente o indivíduo com idade entre doze e dezoito anos incompletos.

Com o intuito de alcançar os objetivos propostos e de compreender de forma mais ampla e profunda a reflexão de mães no que se refere ao diálogo sobre sexualidade com os filhos adolescentes, realizou-se um estudo qualitativo. Nesta pesquisa, foram realizadas entrevistas semiestruturadas e grupos focais, técnicas estas que se mostram adequadas para investigações qualitativas e atenderam aos objetivos deste estudo. Entende-se que a partir do uso de técnicas diferentes é possível captar os diferentes aspectos envolvidos na constituição do objeto que está sendo pesquisado. Dessa forma, foi utilizada a triangulação dos dados coletados. Ou seja, foram combinadas duas técnicas distintas (entrevistas e grupos focais), a fim de conferir 
maior abrangência e profundidade à análise do fenômeno pesquisado (J ovchelovitch, 2000).

Foram realizadas entrevistas semiestruturadas com questões abertas, as quais permitiram o acesso aos dados básicos para a compreensão detalhada das crenças, significações, atitudes, valores e comportamentos dos sujeitos no que se refere ao tema proposto (Gaskell, 2005). Os eixos que nortearam as entrevistas foram os seguintes: 1- Abordagem do tema sexualidade na família; 2- Diálogos sobre sexualidade com o filho adolescente; 3- Assuntos relacionados à sexualidade que são abordados; 4- Necessidade/importância de se tratar do tema da sexualidade com os filhos; 5 - $O$ que os adolescentes esperam dos pais em relação às questões envolvendo a sexualidade neste período do desenvolvimento.

Os grupos focais complementaram as entrevistas, visto que nestes, devido à interação de seus membros, foi possível esclarecer temáticas que emergiram nas entrevistas individuais. Foram utilizadas como disparadores para as discussões grupais falas de meninas que participaram de uma pesquisa anterior que teve como tema o diálogo sobre sexualidade na família. As vinhetas utilizadas foram as seguintes: 1. "Eles acham que a gente não tá preparada pra saber daquilo. Mas a gente tá preparada. Tá chegando a idade, a gente tem que saber disso. A gente tá na idade de saber essas coisas" ( $\mathrm{E}, 13$ anos); 2. "A minha mãe me contava: Se tu beijava tu ia engravidar e daí se tu beijava assim, o homem tinha que comprar uma sementinha e pôr no teu umbigo pra ti ter um nenê, porque senão tu era condenada" ( $T, 13$ anos); 3. "É, tipo quando a gente quer conversar e tipo, "ah não quero conversar sobre isso", daí... tipo eu, quero conversar sobre sexualidade com a minha mãe, mas a minha mãe não fala isso comigo" ( $R, 13$ anos); 4. "O máximo que a mãe me fala é: 'Se tu for fazer alguma coisa, tu usa camisinha' (...) A senhora camisinha... [risos]. É, o que eles mais falam... se prevenir..." (K, 14 anos). As entrevistas e os grupos focais foram realizados nas dependências do CRAS, em uma sala apropriada, sendo gravados e posteriormente transcritos.

\section{Análise dos Dados}

Os dados foram analisados através do método de Análise de Conteúdo Temática, como proposto por Bardin (1977). Para chegar às categorias, as entrevistas foram sendo analisadas primeiro de forma individual, à medida que foram sendo transcritas e, posteriormente, em conjunto. Após esta etapa, os grupos foram também analisados, primeiramente de forma individual e depois procedeu-se a análise da totalidade do material partindo-se para os elementos presentes considerando-se a força discursiva, os sentimentos manifestados, os silêncios ou conflitos em relação à 
temática. Neste trabalho, serão abordadas as seguintes categorias: (1) desafios para o estabelecimento do diálogo sobre sexualidade com os filhos adolescentes; (2) escola e a educação sexual dos adolescentes; (3) educação sexual e saúde pública.

\section{Resultados e Discussão}

1. "Essas coisas assim eu sou meio sem prática de falar": desafios para o estabelecimento do diálogo sobre sexualidade com os filhos adolescentes

Estudos vêm mostrando que, em geral, há um reconhecimento por parte dos pais sobre a importância do diálogo aberto com seus filhos sobre sexo/sexualidade. No entanto, grande parte dos pais manifestam dificuldades para abordarem esta temática com os filhos (Costa, Rabelo, Moraes, Siqueira, \& Cabral, 2014; Dias \& Gomes, 1999; Gonçalves, Faleiro, \& Malafaia, 2013; Gubert, Vieira, Pinheiro, Oliveira, \& Costa, 2009; Nery, Feitosa, Sousa, \& Fernandes, 2015; Predebon, 2002; Queirós et al., 2016; Sevilla et al., 2016), sendo apontados diversos motivos, tais como timidez, vergonha, falta de motivação, sentimento de despreparo, insegurança, receio de que o fato de trazer o tema à tona estimule a iniciação sexual do adolescente, ou até, falta de abertura dos próprios filhos.

O sentimento de despreparo para abordar o tema da sexualidade com os filhos foi referido por algumas mães participantes deste estudo. Além disso, elas manifestaram sentirem-se menos preparadas com relação a informações sobre o assunto, quando comparadas a outras pessoas e aos próprios filhos adolescentes. Esta questão pode ser visualizada nas seguintes falas:

É, não tem o que falar mesmo. Sei lá... Pois é... [silêncio] (...). Eu não sei nem o que te falar, porque estou meio sem prática [riso] (M3, 49 anos, E). Ele [filho] explica para mim, ele diz: "Bah mãe, a senhora ficou para trás. A senhora está perdida no mundo!" (M12, 42 anos, GF1).

Assim, diante da sensação de despreparo, pode haver um fechamento ou uma "fuga do tema" por parte das mães diante das demandas dos filhos por orientações sobre assuntos relacionados à sexualidade. Este aspecto pode ser verificado na fala que segue.

E às vezes tu não sabe como lidar... na hora que perguntam às vezes tu fica meio perdida. (...) Em casa tu tranca para falar. (...) Porque às vezes ele me pergunta e eu fico quieta, numas 
coisas... E eu fico meio perdida... "Tu pergunta para o pai..." (M4, 45 anos, E).

O sentimento de vergonha ao falar sobre sexualidade com os filhos também foi apontado pelas mães participantes. No caso de M14, de acordo com seu relato, esse sentimento teria feito com que ela mantivesse silêncio em relação ao tema, apesar de ter referido as solicitações de esclarecimentos por parte da filha.

Eu nunca expliquei porque ela... porque eu tinha receio de falar para ela e vergonha dela... Com 10 anos já tá me pedindo, já tá me pedindo isso, né, de sexo... Ela foi experimentar, né... já que eu não expliquei para ela... (M14, 48 anos, GF1).

Estudo realizado por Gubert et al. (2009) com mães de adolescentes, de uma comunidade pobre de Fortaleza/Ceará, revelou que elas reconheciam a importância do diálogo sobre sexualidade, mas relataram que o medo e a vergonha por vezes prejudicavam a sua concretização. De acordo com Levisky (1995), a sexualidade pode estar relacionada a algo vergonhoso para os pais, o que pode ser apontado como um legado do período em que eles vivenciaram sua própria adolescência. Desse modo, diante da adolescência dos filhos, os pais podem angustiar-se, principalmente em decorrência das evocações conscientes $e$ inconscientes de suas fantasias e de comportamentos presentes em sua adolescência (Cardoso, 2008; Levisky, 1995; Nery et al., 2015).

Para a participante $\mathrm{M} 12$, o sentimento de vergonha e a dificuldade encontrada para conversar sobre sexualidade, principalmente com o filho, parecem estar ligados à ideia de que conversar sobre sexualidade seria uma tarefa que não combinaria com a função materna. Esta questão pode ser visualizada em sua fala.

Têm muitas mães que não sei... não querem falar, se sentem com vergonha de falar. Porque não é fácil para gente chegar e contar para o filho da gente como é que é... Não sei se é vergonha, o que é... (...). Estou com o meu filho de 15 anos que esses dias me perguntou: “Mãe, quando a minha namorada está menstruada eu não posso manter relação sexual com ela, né?". Eu disse: "Não". "Eu quero que a senhora me explique isso aí". Fica chato... às vezes a gente diz "Tá, daqui a pouquinho eu venho ali". Aí ele fica na sala esperando sentado. "Tá mãe, vai vir?". Aí eu chego até lá para explicar para ele. Mas é difícil. Às vezes as mães, não é porque não quer, mas acho que elas não conseguem... Travam, e eles ficam perguntando... É difícil para uma mãe. Eles são criança, e nós 
somos a mãe deles. Então é bem difícil chegar e dizer o que tá acontecendo... (M12, 42 anos, GF1).

A partir da fala de $M 12$, nota-se que ela parece sensível às dúvidas de seu filho, no entanto, salienta o quanto alguns assuntos relacionados à sexualidade são difíceis de ser tratados. Este aspecto também pode ser percebido nas falas abaixo.

Que sempre têm umas coisas que se fala abertamente, têm outras... umas coisas que tranca... E sexo não é fácil de falar. Tem gente que não fala... têm uns que têm vergonha (M4, 45 anos, E). Só que... é difícil, é difícil a gente abordar isso aí para eles (M15, 30 anos, GF2).

Um dos motivos pelo qual é difícil falar de forma aberta sobre o tema da sexualidade é o fato de que este assunto ainda é envolto por muitos preconceitos, mitos, tabus e por uma forte carga emocional (Gonçalves et al., 2013; Predebon, 2002). Para a psicanálise, a sexualidade é algo que não tem a ver com o Saber cotidiano, pois as concepções freudianas separam o sexo do Saber (Masotta, 1987). Masotta reflete sobre o fato de que, para a perspectiva psicanalítica, as pessoas não adoecem por ignorarem as regras biológicas referentes ao sexo, mas sim porque não querem saber acerca do que é inerente à sexualidade. Desse modo "O sujeito não sabe sobre aquilo que está na origem dos sintomas que suporta (está aí o inconsciente), porque nada quer saber sobre o fato de que não pode saber que não existe Saber sobre o sexual" (Masotta, 1987, p. 26). No entanto, a pulsão não facilita esse saber, já que, conforme apresentado por Freud (1915/1996), o objeto é o que há de mais variável na pulsão, não existindo assim um objeto que lhe seja próprio. O fato de a sexualidade ser reprimida relaciona-se ao que ela possui de enigmático. Quando se reprime é porque não se quer tomar conhecimento de algo que exige ser reconhecido. E o que exige ser reconhecido é justamente $\mathrm{o}$ fato de que não existe um Saber (Masotta, 1987).

Outro aspecto que merece ser destacado é que, a partir dos relatos das participantes, é possível notar uma relação estreita entre o sentimento de despreparo e a dificuldade para abordar o tema da sexualidade com os filhos e suas vivências passadas. As mães relataram um passado marcado por silenciamento e tabus em relação à sexualidade junto a suas famílias durante a infância e adolescência. Este aspecto fica evidente na fala da participante M6:

Bom, eu me criei, como eu te disse, têm coisas que os mais novos sabem que eu não sei. Muitas coisas que dizem eu não sei. Eu não fui criada assim, sabe, solta. Eu me casei com 19 
anos. Eu me criei assim sem saber nada, nem de mãe, nem de pai, nem de irmão, nem de ninguém, entendeu? $E$ até hoje, eu vejo umas gurias de 12, 13 anos falarem em sexo, falando em coisas de sexo que eu não sei o que é. Eu não tenho vergonha de dizer. Eu não sei o que é (M6, 47 anos, E).

O fato de os pais não terem vivenciado momentos de diálogo sobre sexualidade junto a seus próprios pais é um aspecto por vezes utilizado pelos mesmos para justificar a dificuldade para estabelecer um diálogo aberto com seus filhos adolescentes (Costa et al., 2014; Dias \& Gomes, 1999; Gonçalves et al., 2013; Nery et al., 2015; Sevilla et al., 2016). Pesquisa de Dias e Gomes (1999), realizada em Porto Alegre/RS, que teve como participantes pais de adolescentes gestantes pertencentes à grupos populares, revelou que as lembranças dos pais acerca de sua própria vivência familiar durante a adolescência poderiam ter relação com a maneira com que esses pais estabeleciam (ou não) diálogos sobre sexualidade com suas filhas. $O$ estudo mostrou que os pais das adolescentes gestantes informaram que não tiveram seus familiares disponíveis para oferecer informações e dialogar sobre sexualidade, desenvolvendo-se enquanto adolescentes em um meio marcado por proibições, repressões e preconceitos. Assim, os autores apontam a dificuldade destes pais assumirem uma postura diferente da de seus próprios familiares junto a seus filhos adolescentes, considerando que o único modelo conhecido e aprendido seria o da imposição de padrões (Dias \& Gomes, 1999). Em relação a este aspecto, alguns estudos mais recentes realizados com pais mostram o desejo destes de não reproduzirem o modelo de educação sexual recebido em suas famílias, esforçando-se para 'fazer diferente' (Queirós et al., 2016; Savegnago \& Arpini, 2016).

Cabe salientar ainda que as famílias, bem como as relações que nelas se estabelecem, são diversas e, desse modo, a questão dos diálogos sobre sexualidade entre pais e filhos não tem um padrão único. Assim, foi possível constatar que a maioria das mães relatam dificuldades no estabelecimento deste tipo de diálogo, mas há algumas mães que afirmam ter facilidade nesse sentido.

2. "Na escola hoje em dia ensinam, eu acho uma maravilha": a escola e a educação sexual dos adolescentes

A escola, devido ao papel ocupado como lugar de socialização do adolescente, tem se configurado em um meio muito importante para a educação sexual (Borges et al., 2006; Brêtas \& Silva, 2005; Gonçalves et al., 2013; Vilelas Janeiro, 2008). As mães participantes deste estudo referiram de forma significativa à escola como um lugar 
onde seus filhos adquirem informações e recebem orientações sobre sexualidade.

Mas geralmente sobre doenças, essas coisas, elas já aprenderam no colégio, então elas já sabem. Mas às vezes mesmo eles vêm me contar, até às vezes eu nem sei e eles vêm me contar. Que falaram sobre uma doença, sobre isso... sobre camisinha também, tudo elas falam, tudo... Eles estão bem informados (M5, 34 anos, E). E a escola hoje em dia ensina bastante também sobre a sexualidade. Porque aqui no $X$ eles têm palestras, eles têm... é aberto, aberto assim que... eu até fico bã... (M17, 36 anos, GF2).

Houve um reconhecimento por parte das participantes do papel que a escola assume na educação sexual de seus filhos, o que também pôde ser identificado em uma pesquisa realizada com pais de alunos de uma escola privada de Toledo/Paraná, na qual os participantes afirmaram que muitas das informações relativas à sexualidade que os adolescentes possuíam haviam sido transmitidas pela escola (Almeida \& Centa, 2009).

Muitos pais parecem acreditar que os professores estariam mais aptos que eles para tratar do tema com os adolescentes. No entanto, estudos têm apontado certo despreparo dos professores para a abordagem do tema (Brêtas \& Silva, 2005; Moura, Pacheco, Dietrich, \& Zanella, 2011; Valdés, 2005). Ao tratar-se deste assunto, ainda é comum a ocorrência de dúvidas e a transmissão de mitos e ideias preestabelecidas também por parte dos professores (Macedo et al., 2013). Ainda, por vezes, diante das manifestações da sexualidade por parte de crianças e adolescentes no meio escolar, os professores ignoram, ocultam ou reprimem tais comportamentos, apoiados na ideia de que a sexualidade seria um tema para ser tratado somente pela família (Brasil, 1998).

Abordar o tema da sexualidade no contexto escolar é uma questão polêmica, considerando-se os tabus que circundam esta temática e a variedade de pontos de vista, crenças e valores dos diversos atores envolvidos, como alunos, pais e professores (Castro, Abramovay, \& Silva, 2004). Nesse sentido, por vezes pode haver críticas por parte dos pais quanto ao tipo de informação sobre sexualidade transmitida pela escola aos adolescentes e também em relação à forma como se dá essa abordagem. A fala de M1 ilustra tal situação:

Isso as professora estão explicando pra eles. Aí ficavam faceiros, todos curiosos, diziam que podiam fazer, que podiam manter [relações sexuais], que não tinha quem atacasse eles, não tinha regra nenhuma, eles não precisavam ter insegurança, eles podiam fazer. Mas aí, ensinam eles começar a fazer e rir e 
achar lindo. Eu acho que eles tinham que ensinar quem estivesse já com 15, 16, acima... menor não. Sei lá... Tinha que ter idade, regra, né. ( $M 1,38$ anos, E).

De forma semelhante, Castro et al. (2004) constataram em sua pesquisa, que ouviu centenas de pais, professores e alunos em quatorze capitais brasileiras, casos de pais que afirmavam que a escola não podia ser um "lugar para ensinar saliências". Apesar disso, também em concordância com Castro et al. (2004), a maioria das mães participantes da presente pesquisa pareceu estar de acordo com a forma como é tratada a questão da sexualidade no âmbito escolar. Hoje se percebe que muitos pais reivindicam a orientação sexual nas escolas, uma vez que reconhecem não só a sua importância para crianças e adolescentes, mas também a dificuldade de conversar de forma aberta sobre o tema na família (Brasil, 1998; Gonçalves et al., 2013).

As falas das mães participantes denotam que os assuntos relacionados à sexualidade abordados na escola geralmente referemse a questões biológicas, voltadas para as questões reprodutivas e preventivas. Em concordância com esta percepção, vários estudos têm constatado que, nas escolas, a sexualidade geralmente é abordada priorizando-se seus aspectos biológicos e tratada como sinônimo de genitalidade, desconsiderando-se, assim, suas dimensões afetivas e emocionais (Borges et al., 2006; Brêtas \& Silva, 2005; Cardoso, Figueiredo, \& Pecorari, 2007; Gonçalves et al., 2013; Moura et al., 2011; Oliveira, 2012). Além disso, muitas vezes o tema é abordado de uma forma excessivamente didática, sem discussão e reflexão crítica, reduzindo a complexidade do tema e a interdisciplinaridade. Pesquisa realizada por Macedo et al. (2013) junto a adolescentes do município de Jandaíra, no Rio Grande do Norte, matriculados na Unidade de Educação de Jovens e Adultos (EJA), mostrou que a abordagem da temática da sexualidade era feita de forma superficial na escola, restringindo-se à ênfase ao uso da camisinha e à prevenção de doenças sexualmente transmissíveis (Macedo et al., 2013).

De acordo com os Parâmetros Curriculares Nacionais (PCN), "a orientação sexual na escola deve ser entendida como um processo de intervenção pedagógica que tem como objetivo transmitir informações e problematizar questões relacionadas à sexualidade, incluindo posturas, crenças, tabus e valores a ela associados" (Brasil, 1997, p. 28). A orientação sexual é entendida, a partir dos PCN's, como um dos temas transversais a serem abordados na escola, ou seja, deveria permear toda a prática educativa e ser contemplada pelas diversas áreas do conhecimento, não se restringindo a uma disciplina específica. No entanto, o que comumente tem se observado é que a tarefa de abordar este tema junto aos alunos recai 
geralmente sobre os professores das ciências biológicas. Em relação a este aspecto, Brêtas e Silva (2005) e Oliveira (2012) afirmam que a redução da sexualidade apenas ao seu aspecto reprodutivo não é um fato recente e poderia ser apontada como uma consequência da negação do sexo como fonte de prazer. De acordo com Altmann (2013), os PCN's se apresentaram como uma proposta curricular sem atenção e investimento na formação profissional, motivo pelo qual foram criticados por instâncias acadêmicas e de militância social. Diante destes desafios, sugere-se a colaboração de especialistas na realização de trabalhos de esclarecimento e formação sistemática de professores (Castro et al., 2004).

Desse modo, se fizeram presentes relatos que consideram que a família e a escola deveriam atuar como complementares no que se refere aos diálogos sobre sexualidade com os adolescentes.

Na minha opinião, não acho que seja suficiente, mas eu acho que se os pais não apoiarem, não ajudarem também, só a escola, né, não é... Às vezes eles podem até ouvir e achar que não é... Eu acho que se os pais participarem junto com a escola, eu acho que é bem melhor. (M5, 34 anos, E). Então, eu acho que a escola faz a parte dela e em casa tu faz a tua, esclarece. Acredito que seja isso. Tu tem que esclarecer o que muitas vezes o professor não tem tempo de esclarecer ou passa a informação de repente corrido (M9, 33 anos, E).

De forma semelhante, um estudo realizado em Lisboa com adolescentes, pais e professores mostrou que a maioria dos familiares participantes acreditava que a escola era a instituição destinada à educação sexual dos filhos, a qual deveria ser complementada no âmbito familiar. Em concordância com o exposto, professores e adolescentes compartilhavam da ideia de que a família e a escola deveriam atuar como complementares na educação sexual dos adolescentes. Além disso, a maioria dos pais participantes do estudo demonstrou aprovação em relação à implementação de programas de educação sexual nas escolas (Vilelas Janeiro, 2008). Assim, o autor afirma que "se à família cabe um relacionamento mais íntimo e profundo, à escola caberá um relacionamento mais planejado e sistemático" (p. 383).

De acordo com os Parâmetros Curriculares Nacionais, a sexualidade deveria ser abordada em primeiro lugar no contexto privado das relações familiares. Desse modo, explícita ou implicitamente, podem ser comunicados os valores que cada família assume como seus e espera que a criança ou o adolescente adote. Por outro lado, é tarefa da escola a abordagem dos diferentes pontos de vista, valores e crenças presentes na sociedade, a fim de ajudar o aluno a estabelecer referências para si através da reflexão. $O$ apoio dos pais 
ao trabalho desenvolvido na escola junto a seus filhos pode ser uma importante parceria para o sucesso da orientação sexual nesta instituição (Brasil, 1997).

3. "Tem tudo também nos postos de saúde, dão preservativo, anticoncepcional, tudo": educação sexual e saúde pública

A saúde pública também parece estar assumindo um papel importante para essas mães, uma vez que, conforme seus relatos, elas recorrem muitas vezes às Unidades Básicas de Saúde ou às equipes da Estratégia de Saúde da Família, a fim de que os profissionais da saúde prestem esclarecimentos sobre sexualidade aos seus filhos adolescentes. Isto parece ocorrer tanto em relação aos meninos quanto em relação às meninas. As mães esperam esclarecimentos por parte dos profissionais principalmente sobre prevenção às doenças sexualmente transmissíveis e à gravidez, além de buscarem preservativos e anticoncepcionais.

Porque hoje em dia tem esses programas, tem vocês [psicólogos], tem os programas na escola, tem tudo. Tem tudo também nos postos de saúde, dão preservativo, dão anticoncepcional, tudo (M7, 47 anos, E). A minha filha, eu levei ela no médico, ela não teve relação ainda (M15, 30 anos, GF2). Ele [filho] vai ter que ir no médico para ele ver como é a verdade, quais são as doenças que pega se tu não te cuida, que nem eu disse pra ele (M8, 33 anos, E).

De acordo com Santos (2011), a partir de uma pesquisa realizada com profissionais de equipes da Estratégia de Saúde da Família da cidade de Santa Maria/RS, muitos pais encaminhavam seus filhos à unidade de saúde, para que tais assuntos fossem esclarecidos e discutidos com a equipe. Estes profissionais apontaram que isso ocorria devido às dificuldades das famílias em abordar assuntos relacionados à sexualidade com os filhos adolescentes. No entanto, em alguns casos, estes esclarecimentos podem ter para as mães um caráter complementar ao que elas já teriam transmitido. Esta ideia se faz presente na fala de M16:

Ela tem namorado, eu trouxe no médico, pedi para o médico explicar, orientar ela. Porque não adianta proibir, amanhã depois ela vai transar. (...) Mas isso foi interessante, que eu trouxe ela no médico e o médico explicou tudo isso para ela também. Eu fui junto. Ele explicou tudo que eu já tinha explicado, que eu sabia até de cor. Mas é bom repetir, repetir para ela. Porque a gente... como tu falou, um filho tu cria, mas uma Aids? Uma doença venérea? (M16, 41 anos, GF2). 
Em relação a esse aspecto, alguns autores que têm se debruçado sobre o estudo da saúde pública questionam se, quando o adolescente busca um serviço de saúde, ele recebe a atenção ideal e se estes serviços encontram-se bem preparados para acolhê-lo. Nesse sentido, é imprescindível que o profissional de saúde tenha para com este adolescente uma atitude de cordialidade, acolhida, compreensão, respeito à sua singularidade e isenta de julgamentos (Santos, Andrade, Mello, \& Maia, 2014; Santos \& Ressel, 2013; Tôrres, Nascimento, \& Alchieri, 2013).

Santos e Ressel (2013) afirmam que, na prática, percebe-se que a procura dos adolescentes pelo serviço de saúde ocorre geralmente pelos seguintes motivos: teste de gravidez, consulta pré-natal, busca por anticoncepcionais e preservativos masculinos. Os autores destacaram ainda que uma situação que frequentemente traz dificuldade para o profissional de saúde é ter que lidar com o início da vida sexual do adolescente (Santos \& Ressel, 2013).

Os profissionais da saúde também foram referidos pelas mães como possíveis interlocutores que podem ser consultados para sanar dúvidas sobre como dialogar sobre sexualidade com os filhos adolescentes: Então assim, o que tu não teve, vai procurar dar para o teu filho. Procura um médico, procura um psicólogo, pergunta como tu deve falar, sabe? (M9, 33 anos, E).

Ao trabalhar questões sobre sexualidade, o profissional da saúde deveria levar em conta as particularidades de cada família e agir de forma a apoiá-la, protegê-la e fortalecê-la. Seria fundamental que a família e o profissional da saúde compartilhassem conhecimentos e ações com o objetivo de orientar os adolescentes para exercerem sua sexualidade com responsabilidade. De acordo com Almeida e Centa (2009) e Queirós et al. (2016), o profissional da enfermagem é um dos que se encontra habilitado para desenvolver ações de educação em saúde e, portanto, pode atuar no planejamento e na implementação de ações que favoreçam a saúde do adolescente e também que apoiem sua família.

Salienta-se que a orientação sobre a saúde sexual do adolescente não é uma tarefa exclusiva da enfermagem, cabendo também aos demais profissionais desempenhar esse papel. No entanto, quem mais parece estar se ocupando desta função tem sido o profissional da enfermagem. Isto fica evidente nas produções científicas sobre orientação sexual ao adolescente, as quais são em grande parte provenientes desta área.

Em contrapartida, estudos mostram que um baixo percentual de adolescentes afirma ter participado de atividades educativas voltadas para a sexualidade, desenvolvidas por alguma unidade de saúde (Borges et al., 2006; Santos et al., 2014; Tôrres et al., 2013). Além disso, adolescentes da zona urbana do município de Pau dos Ferros RN, participantes do estudo de Tôrres et al. (2013), relataram que, 
apesar de sentirem-se bem acolhidos nas unidades de saúde, não costumavam procurar essas instituições para conversar sobre sexualidade ou buscar atendimento voltado para questões sexuais.

Tendo em vista essa baixa procura dos adolescentes por atendimentos nas unidades de saúde, é importante considerar que estudos mostram que, em geral, os profissionais desta área não possuem conhecimento sobre programas voltados para 0 adolescente, como o PROSAD - Programa de Saúde do Adolescente, tampouco desenvolvem ações específicas destinadas a esse público, no sentido da promoção e prevenção à saúde (Santos, 2011; Tôrres et al., 2013).

O PROSAD, proposto pelo Ministério da Saúde, foi criado no intuito de apresentar normas e critérios para o atendimento específico do público adolescente, e deveria ser desenvolvido em conjunto com a Estratégia de Saúde da Família (Santos, 2011). No entanto, apesar da criação de programas pelo governo, que propõe um melhor e maior atendimento ao adolescente, há uma escassez de capacitação aos profissionais, a fim de que possam tomar como base estes programas para que sejam efetivamente planejadas e implementadas ações voltadas à saúde do adolescente (Santos, 2011; Tôrres et al., 2013).

\section{Considerações finais}

Desse modo, perante a evidente dificuldade apontada pelas participantes com relação aos diálogos sobre sexualidade entre pais e filhos adolescentes, salienta-se a importância de programas de orientação sexual voltados não apenas para os adolescentes, mas, também, e em especial, para pais e mães. Estes programas poderiam focalizar crenças, mitos e tabus em relação à sexualidade, além de incentivar o diálogo no contexto familiar. Assim, os pais poderiam minimizar suas angústias com relação à adolescência dos filhos, principalmente no que se refere à manifestação de sua sexualidade.

Destaca-se que as instituições escolares e de saúde têm papel fundamental na orientação sexual dos adolescentes. Salienta-se também a importância de capacitar os profissionais de saúde e educação, uma vez que estas instituições acolhem adolescentes e podem atuar como complementares ao papel desempenhado pelos pais, além de facilitadoras da construção do diálogo sobre sexualidade entre pais e filhos adolescentes. Além disso, é importante considerar que o conhecimento adquirido pelos filhos nestas instituições pode se tornar fonte de informação para as mães, ampliando a abordagem do tema e sua reflexão, levando em conta o universo onde o estudo foi realizado, ou seja, com mães usuárias de 
um CRAS, que podem estar tendo poucas oportunidades de tratar do tema.

Nesse sentido, parece ser importante destacar que existem atribuições que são específicas de cada instituição. À escola caberia um caráter mais informativo e pedagógico, dando a dimensão tanto do corpo biológico como também da construção social acerca do tema. À saúde caberiam orientações quanto ao uso dos métodos contraceptivos e sua utilização, assim como do exercício da sexualidade e dos cuidados inerentes à vida sexual ativa. Por outro lado, à família cabe a capacidade de escuta, de lidar com as angústias, incertezas e conflitos que são inerentes à sexualidade humana, algo que não será esgotado com as informações e orientações que forem recebidas no âmbito da saúde e da educação.

Assim, partindo da premissa teórica adotada nesse artigo de que a sexualidade é em si enigmática, talvez a tarefa mais importante que está endereçada aos pais é justamente a capacidade de lidar com esse não saber. Dentro desse escopo, não se esperaria dos pais a resposta, mas sim a capacidade de escutar, de dar um lugar para a angústia e a pluralidade de sentimentos que invadem os adolescentes com relação às questões da sexualidade. Não haveria, portanto, um conhecimento a ser esgotado com relação às questões que envolvem a sexualidade, mas o reconhecimento dessa peculiaridade deveria impulsionar que pudéssemos falar sobre o tema, de forma a evitar que o silêncio seja a resposta ao saber que não portamos.

Abrir espaço para falar sobre esse tema é um dos aspectos que objetivamos destacar ao final desse estudo. Nesse sentido, parece ser importante também considerar que aspectos socioculturais atravessam essa vivência, de forma que a participação da escola e da saúde se convertem em um importante recurso para os adolescentes e suas famílias, considerando que essas instituições estão inseridas em contextos territoriais de proximidade com o cotidiano dos adolescentes.

Uma das questões que se constituem numa importante contribuição desse estudo é destacar que os pais não devem deixar os adolescentes a mercê de suas angústias. Assim, é importante ponderar que, mesmo que estejamos imersos num contexto onde a sexualidade parece naturalizada, isso não implicaria em dispensar a família e as instituições de suas tarefas em torno da temática, considerando serem inesgotáveis suas demandas.

Quanto às possíveis contribuições da Psicologia em relação a esta questão, sugere-se que, em espaços de atenção à saúde e assistência onde haja inserção do psicólogo, como Centros de Referência em Assistência Social, Unidades Básicas de Saúde, escolas e projetos sociais, sejam criadas ações voltadas para a educação sexual. Estas ações poderiam ser desenvolvidas através de oficinas e grupos de discussão voltados tanto para adolescents, sobre questões que 
envolvem a sexualidade, bem como para seus familiares, oferecendo espaços de escuta, reflexão e trocas sobre como lidar com as demandas dos adolescentes referentes a essa temática.

O intuito deste estudo não foi generalizar os resultados aqui apresentados, mas apresentar de forma ampla e profunda as concepções das mães de adolescentes participantes do estudo, pertencentes a um contexto específico. As limitações do estudo podem estar no fato de ter incluído como participantes apenas as mães dos adolescentes. Assim, sugere-se que estudos futuros possam ampliar o olhar da família a partir da inclusão de outros membros, em especial o pai, considerando a crescente busca pelo compartilhamento da responsabilidade parental e da horizontalidade no exercício da parentalidade. Destaca-se ainda a importância de estudos que possam integrar profissionais da educação e da saúde, considerando a complexidade do tema e as atuais transformações que a família vem sofrendo, incluindo a pluralidade e as alterações nos papéis.

\section{Referências}

Almeida, A. C. C. H., \& Centa, M. L. (2009). A família e a educação sexual dos filhos: implicações para a Enfermagem. Acta Paulista de Enfermagem, 22(1), 71-76.

Altmann, H. (2013). Diversidade sexual e educação: desafios para a formação docente. Sexualidad, Salud y Sociedad, 13, 69-82.

Arpini, D. M., \& Witt, C. S. (2015). As múltiplas formas de ser adolescente. Em H. R. Campos, \& S. M. G. Sousa (Eds.). Emocore: experiências grupais na constituição da adolescência (pp. 11-28). Goiânia: EDUFRN/Ed. PUC Goiás.

Bardin, L. (1977). Análise de conteúdo. Lisboa: Editora 70.

Borges, A. L. V., Nichiata, L. Y. I., \& Schor, N. (2006). Conversando sobre sexo: a rede sociofamiliar como base de promoção da saúde sexual e reprodutiva de adolescentes. Revista Latinoamericana de Enfermagem, 14(3), 422-427.

Brandão, E. R. (2004). Iniciação sexual e afetiva: exercício da autonomia juvenil. In M. L. Heilborn (Ed.), Família e sexualidade (pp. 63-86). Rio de Janeiro, RJ: Editora FGV.

Brasil. (1990). Estatuto da Criança e do Adolescente. Lei Federal 8.069/1990. Brasília.

Brasil. (1997). Parâmetros curriculares nacionais: apresentação dos temas transversais, ética. Secretaria de Educação Fundamental. Brasília: MEC/SEF.

Brasil. (1998). Parâmetros Curriculares Nacionais: Temas Transversais: Orientação Sexual (pp. 285-336). Ministério da Educação. Brasília: MEC. 
Brêtas, J. R. S., \& Silva, C. V. (2005). Orientação sexual para adolescentes: relato de experiência. Acta Paulista de Enfermagem, 18(3), 326-333.

Cardoso, L. R. D., Figueiredo, T. F. B., \& Pecorari, E. P. D. N. (2007). Escolas do ensino fundamental estão desenvolvendo programa de orientação sexual? Psicologia Argumento, 25(51), 385-391.

Cardoso, M. R. (2008). Transgressão pulsional e geracional: a perpetuação da adolescência. In M. R. Cardoso, \& F. Marty (Eds.), Destinos da adolescência (pp. 69-80). Rio de Janeiro: 7 Letras.

Castro, M. G., Abramovay, M., \& Silva, L. B. (2004). Juventudes e sexualidade. Brasília: UNESCO Brasil.

Corso, D. L., Corso, M. (2011). A psicanálise na terra do nunca: ensaios sobre a fantasia. Porto Alegre: Penso.

Costa, M. A., Rabelo, N. S., Moraes, I. C. M., Siqueira, F. C. M., \& Cabral, E. S. M. (2014). Fatores que obstam na comunicação entre pais e filhos adolescentes sobre sexualidade. Revista de Enfermagem da UFSM, 4(1), 123-132.

Dias, A. C. G., \& Gomes, W. B. (1999). Conversas sobre sexualidade na família e gravidez na adolescência: a percepção dos pais. Estudos de Psicologia, 4(1), 79-106.

Emmanuelli, M. (2008). A clínica da adolescência. In M. R. Cardoso, \& F. Marty (Eds.), Destinos da adolescência (pp. 17-38). Rio de Janeiro: 7 Letras.

Freud, S. (1996). Os instintos e suas vicissitudes. In J. Salomão (Ed.), Edição standard brasileira das obras psicológicas completas de Sigmund Freud. (Vol. 14, pp. 115-144). Rio de Janeiro: I mago. (Original publicado em 1915).

Freud, S. (1996). Três ensaios sobre a teoria da sexualidade. In J. Salomão (Ed.), Edição standard brasileira de obras completas de Sigmund Freud (Vol. 7, pp. 117-231). Rio de Janeiro: I mago. (Original publicado em 1905).

Gaskell, G. (2005). Entrevistas individuais e grupais. In M. W. Bauer, $\&$ G. Gaskell (Eds.), Pesquisa qualitativa com texto, imagem e som: um manual prático (pp. 64-89). Petrópolis: Vozes.

Gonçalves, R. C., Faleiro, J. H., \& Malafaia, G. (2013). Educação sexual no contexto familiar e escolar: impasses e desafios. Holos, 29(5), 251-263.

Gubert, F. A., Vieira, N. F. C., Pinheiro, P. N. C., Oliveira, E. N., \& Costa, A. G. M. (2009). Cuidado de enfermagem na promoção do diálogo mãe e filha adolescente: estudo descritivo. Brazilian Journal of Nursing, 8(3). Recuperado em 5 de setembro de 2015, de http://www.objnursing.uff. br/index.php/nursing/article/view/j. 1 676-4285.2009.2648/578. 
Jovchelovitch, S. (2000). Representações sociais e esfera pública: a construção simbólica dos espaços públicos no Brasil. Petrópolis: Vozes.

Levisky, D. L. (1995). Adolescência: reflexões psicanalíticas. Porto Alegre: Artes Médicas.

Macedo, S. R. H., Miranda, F. A. N., Pessoa Junior, J. M., \& Nobrega, V. K. M. (2013). Adolescência e sexualidade: scripts sexuais a partir das representações sociais. Revista Brasileira de Enfermagem, 66(1), 103-109.

Marty, F., \& Cardoso, M. R. (2008). Adolescência: um percurso franco-brasileiro. In M. R. Cardoso, \& F. Marty (Eds.), Destinos da adolescência (pp. 9-16). Rio de Janeiro: 7 Letras.

Masotta, O. (1987). O comprovante da falta: lições de introdução à psicanálise (M. A. B. Cintra, trad.). Campinas: Papirus.

Mayorga, C. (2006). Identidades e adolescências: uma desconstrução. Pesquisas e Práticas Psicossociais, 1(1), 1-20.

Moura, A. F. M., Pacheco, A. P., Dietrich, C. F., \& Zanella, A. V. (2011). Possíveis contribuições da psicologia para a educação sexual em contexto escolar. Psicologia Argumento, 29(67), 437-446.

Nery, I. S., Feitosa, J. J. M., Sousa, A. F. L., \& Fernandes, A. C. N. (2015). Abordagem da sexualidade no diálogo entre pais e adolescentes. Acta Paulista de Enfermagem, 28(3), 287-92.

Oliveira, D. L. (2012). Sexo e saúde na escola: isso não é coisa de médico? Em D. E. E. Meyer et al. (Eds.), Saúde, sexualidade e gênero na educação de jovens (pp. 103-112). Porto Alegre: Editora Mediação.

Predebon, J. C. (2002). Conversando sobre sexo na família com filhos adolescentes. In A. Wagner (Ed.), Família em cena: tramas, dramas e transformações (pp. 159-171). Petrópolis: Vozes.

Preto, N. G. (1995). Transformações do sistema familiar na adolescência. In B. Carter, \& M. McGoldrick (Eds.), As mudanças no ciclo de vida familiar: uma estrutura para a terapia familiar (pp. 223-247, M. A. V. Veronese, trad.). Porto Alegre: Artmed.

Queirós, P. S, Pires, L. M., Matos, M. A., Junqueira, A. L. N., Medeiros, M., \& Souza, M. M. (2016). Concepções de pais de adolescentes escolares sobre a sexualidade de seus filhos. Revista Rene, 17(2), 293-300.

Roudinesco, E. (2003). A família em desordem. Rio de Janeiro: Jorge Zahar Editor.

Ruffino, R. (2004). A condição traumática da puberdade na contemporaneidade e a adolescência como sintoma social a ela articulada. Textura: Revista de Psicanálise, 4(4), 1-12. 
Santos, B. R. (2011). Estratégia de saúde da família e o atendimento aos adolescentes. Dissertação de Mestrado, Universidade Federal de Santa Maria, Santa Maria, RS, Brasil.

Santos, C. C., \& Ressel, L. B. (2013). O adolescente no serviço de saúde. Adolescência \& Saúde, 10(1), 53-55.

Santos, J. S., Andrade, R. D., Mello, D. F., \& Maia, M. A. C. (2014). Educação em saúde na adolescência: contribuições da Estratégia Saúde da Família. Revista da Sociedade Brasileira de Enfermeiros Pediatras, 14(1), 20-6.

Sarti, C. A. (2004). O jovem na família: o outro necessário. Em R. Novaes, \& P. Vannuchi (Eds.), Juventude e sociedade: trabalho, educação, cultura e participação (pp. 115-129). São Paulo, Brasil: Editora Fundação Perseu Abramo.

Savegnago, S. D. O., \& Arpini, D. M. (2013). Conversando sobre sexualidade da família: olhares de meninas de grupos populares. Cadernos de Pesquisa, 43(150), 924-947.

Savegnago, S. D. O., \& Arpini, D. M. (2016). Atravessamentos das histórias maternas na relação com filhos(as) adolescentes e a sexualidade. Contextos Clínicos, 9(2), 178-193.

Sevilla, T. M., Sanabria, J. P., Orcasita, L. T., \& Palma, D. M. (2016). Consistencies and discrepancies in communication between parents and teenage children about sexuality. Paidéia, 26(64), 139-147.

Sousa, L. B., Fernandes, J. F. P., \& Barroso, M. G. T. (2006). Sexualidade na adolescência: análise da influência de fatores culturais presentes no contexto familiar. Acta Paulista de Enfermagem, 19(4), 408-13.

Sprinthall, N. A., \& Collins, W. A. (2003). Psicologia do adolescente: uma abordagem desenvolvimentista. Lisboa: Fundação Calouste Gulbenkian.

Tôrres, T. R. F., Nascimento, E, G. C., Alchieri, J. C. (2013). O cuidado de enfermagem na saúde sexual e reprodutiva dos adolescentes. Adolescência \& Saúde, 1(supl. 1), 16-26.

Valdés, T. (2005). Socialização em sexualidade no Chile: adolescentes de camadas populares urbanas. Em M. L. Heilborn, L. F. D. Duarte, C. Peixoto, \& M. L. de Barros (Eds.), Sexualidade, família e ethos religioso (pp. 315-342). Rio de Janeiro, Brasil: Garamond.

Vilelas Janeiro, J. M. S. (2008). Educar sexualmente os adolescentes: uma finalidade da família e da escola? Revista Gaúcha de Enfermagem, 29(3), 382-390. 


\section{Endereço para correspondência \\ Sabrina Dal Ongaro Savegnago}

Universidade Federal do Rio de Janeiro - UFRJ

Programa de Pós-Graduação em Psicologia

Av. Pasteur, 250, Pavilhão Nilton Campos, 2o andar, Urca, CEP 22290-902, Rio de Janeiro - RJ, Brasil

Endereço eletrônico: sabrinadsavegnago@gmail.com

\section{Dorian Mônica Arpini}

Universidade Federal de Santa Maria - UFSM

Programa de Pós-Graduação em Psicologia

Campus Universitário, Camobi, CEP 97105-900, Santa Maria - RS, Brasil

Endereço eletrônico: monica.arpini@gmail.com

Recebido em: 23/09/2015

Reformulado em: 18/11/2016

Aceito em: 18/11/2016

\section{Notas}

* Mestre em Psicologia pelo Programa de Pós-Graduação em Psicologia da Universidade Federal de Santa Maria. Doutoranda em Psicologia pelo Programa de Pós-Graduação em Psicologia da Universidade Federal do Rio de Janeiro.

** Doutora em Psicologia Social pela Pontifícia Universidade Católica de São Paulo. Professora Titular do Departamento de Psicologia e do Programa de Pós-Graduação em Psicologia da Universidade Federal de Santa Maria.

${ }^{1}$ A família se constitui em um sistema complexo que se encontra em constante mudança e assume uma variedade de formas de apresentação, por fazer parte dos dinamismos próprios das relações sociais e dos processos históricos e culturais. Nos reportamos ao conceito de família a partir de suas funções, como propiciar relações afetivas, socialização e proteção aos filhos, sendo que tais funções independem da configuração familiar estabelecida. É inerente à condição de pais o dever de educar, cuidar e prover. Além da pluralidade de suas configurações, outro aspecto que caracteriza a família hoje é a crescente horizontalidade das relações e o maior compartilhamento do exercício parental. Para maiores referências sobre o tema, sugere-se a consulta de Roudinesco (2003).

Apoio financeiro: CAPES - bolsa de mestrado concedida para a primeira autora.

Este artigo de revista Estudos e Pesquisas em Psicologia é licenciado sob uma Licença Creative Commons Atribuição-Não Comercial 3.0 Não Adaptada. 